\title{
Contributions to the Functional Analysis of Single-Trial Free Recall
}

\author{
John T. Wixted and Jack J McDowell \\ Emory University
}

\begin{abstract}
An extensive body of research generated by the now outmoded dual store model has produced a set of functional principles of single-trial free recall. One principle, termed the ratio rule, describes the properties of the recency effect, while several others based upon laws of rehearsal have becn advanced to account for the primacy effect. These principles, which may eventually establish the foundation for a more comprehensive theory of list memory, were tested in three experiments. The first two experiments showed that when rehearsal is eliminated (Experiment 1) or equated (Experiment 2), reliable primacy and recency effects are obtained. The third experiment demonstrated that the effectiveness of rehearsal during list presentation declines monotonically as a function of serial position. These results contrast with the prevailing functional account of both primacy and recency effects and suggest several new lines of inquiry into the subject.
\end{abstract}

For almost a century, and especially in the last 30 years, psychologists have endeavored to understand the primacy and recency effects of free recall (Murdock, 1962). The approaches taken to explain those effects in the past can be roughly divided into two categories. One approach attributed serial position effects to properties determined solely by an item's relative position within a list. Murdock's (1960) theory of stimulus distinctiveness exemplified this type of analysis. A second approach emphasized the interaction between cognitive systems and behavioral strategies such as rehearsal (e.g. Atkinson \& Shiffrin, 1968; Rundus, 1971; Waugh \& Norman, 1965).

The most widely researched theory of list memory, the dual store model, was of the latter type. This model dominated the memory field for a number of years but eventually fell from favor with the growing accumulation of disconfirming evidence (Crowder, 1976, 1982). Although a viable successor has yet to emerge, the vigorous empirical inquiry generated by the dual store model has produced an increasingly refined functional analysis of serial position effects. The term functional analysis, as used here, refers to the investigation of lawful empirical relations between a set of independent variables (e.g., number of rehearsals) and the dependent variable of interest (usually probability of recall). Although such an analysis does not directly address the question of mechanism, it may, in the long run, facilitate the development of mechanistic explanations by imposing structure on an otherwise disparate array of findings.

A review of the research on single-trial free recall reveals the emergence and further refinement of at least two classes of empirical principles that roughly parallel the historical distinction between rehearsal and item position accounts. An

This article is based on a dissertation submitted to Emory University by the first author. We gratefully acknowledge the advice of $E$. Winograd and L. Barsalou during the early stages of the project.

Correspondence concerning this article should be addressed to the first author, who is now at the Department of Psychology, C-009, University of California. San Diego, La Jolla, California 92093. early rehearsal principle that was derived from the dual store model stated that the more time devoted to rehearsal of a given word, the greater the probability of delayed recall (Rundus, 1971). According to this view, the primacy effect of single-trial free recall stems from the extra rehearsal received by the first few items of a list. Although appealing in its simplicity, this hypothesis proved to be inadequate when a number of studies showed that, under some conditions, memory for rehearsed items is no better than that for unrehearsed items (e.g., Glenberg, Smith, \& Green, 1977; Jacoby \& Bartz, 1972; Meunier, Ritz, \& Meunier, 1972; Modigliani \& Seamon, 1974; Rundus, 1977).

Two subsequent accounts, one based on levels of processing theory (Craik \& Lockhart, 1972) and the other based on the notion of rehearsal distribution (Modigliani, 1976), have attempted to more clearly define the conditions under which rehearsal will be effective. Craik and Watkins (1973) proposed the existence of two types of rehearsal: one characterized by rote repetition (maintenance rehearsal) and the other characterized by the formation of semantic associations (elaborative rehearsal). According to this theory, only the latter form of rehearsal serves to strengthen and enrich the memory trace. Modigliani $(1976,1980)$, on the other hand, suggested that the temporal distribution of rehearsal determines its effect on later recall. Specifically, rehearsals that are separated by at least a few seconds (distributed rehearsals) exert a much greater strengthening effect than those occurring in rapid succession (immediate rehearsals). As with their predecessor, both of these rehearsal principles have been invoked to account for the primacy effect of single-trial free recall. Indeed, that rehearsal is in some way responsible for the primacy effect appears to be a widely accepted notion (Bruce \& Papay, 1972; Crowder, 1976).

With regard to the recency effect, item position principles have generally been preferred to rehearsal accounts. Before the advent of the dual store model, retention interval (RI) was often implicitly assumed to be a factor in the production of the recency effect (e.g., Murdock, 1974; Tulving \& Arbuckle, 1963). Because the position of the last few items of a list 
ensures that they are associated with the shortest RI, a recency effect was not very surprising. Nevertheless, the results of a number of studies now suggest that a more precise determinant of the magnitude of the recency effect is the ratio of the interpresentation interval (IPI) to the delay over which a word must be recalled (i.e., RI). This principle is referred to as the ratio rule (Crowder, 1976). Support for the ratio rule has been provided by a number of studies that have varied IPI while using a distractor procedure to prevent rehearsal (Bjork \& Whitten, 1974; Tzeng, 1973; Glenberg et al., 1980; Glenberg, 1984). Indeed, Glenberg, Bradley, Kraus, and Renzaglia (1983) showed that this principle remains accurate over a very wide range of temporal parameters.

From a functional standpoint, the current appraisal of serial position effects is that the primacy effect is exclusively a rehearsal phenomenon, the specifics of which are unclear, and the recency effect is primarily an item position phenomenon governed by the ratio rule. Note that neither a rehearsal principle nor the ratio rule alone predicts both a primacy and a recency effect (Crowder, 1976). Because the amount of rehearsal received by list items decreases as a function of serial position (Rundus, 1971), a rehearsal account alone would predict a serial position curve characterized by a monotonically decreasing function. Similarly, because the function IPI/ $\mathrm{RI}$ is smallest for the initial items and largest for the terminal items, a pure item position account would predict a monotonically increasing serial position function. Together, however, these two principles offer an interpretation of both primacy and recency effects.

The purpose of the three experiments described here was to test and further develop this functional account of free recall. The primary issue addressed by the first two experiments concerns the form of the serial position curve when rehearsal is eliminated (Experiment 1) or equated (Experiment 2). Under those conditions, the ratio rule alone should govern the resulting serial position function, and a primacy effect should not be observed. The third experiment was designed to examine more closely the role of rehearsal in contributing to serial position effects.

\section{Experiment 1}

The results of many experiments suggest that when steps are taken to reduce or eliminate rehearsal during list presentation, the primacy effect is selectively attenuated. Some studies have shown, for example, that as the rate of presentation increases (thereby decreasing the time available for rehearsal), the magnitude of the primacy effect reliably decreases (Murdock, 1962). Other studies, using incidental learning procedures to discourage rehearsal, have reported serial position curves characterized by the notable absence of a primacy effect (Glenberg, 1984; Marshall \& Werder, 1972). Still other studies have imposed distractor tasks between word presentations in order to forcibly prevent rehearsal (e.g., Bjork \& Whitten, 1974; Glenberg, 1984; Glenberg et al., 1980; Tzeng, 1973). Typically, this procedure results in a reduced primacy effect, while the recency effect remains largely intact. All of these findings point to the role of rehearsal in producing the primacy effect.
On the other hand, even when the rate of item presentation is very high (e.g., two items per second) a small primacy effect is reliably obtained despite the limited time available for differential rehearsal (Crowder, 1970; Murdock \& Walker, 1969). Further, in most experiments using rehearsal-preventing procedures (e.g., Bjork \& Whitten, 1974; Glenberg et al., 1980), a reduced but definite primacy effect can often be detected. When extremely demanding distractor tasks are used (e.g., Glenberg, 1984), the primacy effect is climinated, but it is not clear whether this is due to the elimination of rehearsal or to the introduction of massive retroactive interference that may mask the presence of a small primacy effect. The most conservative interpretation of past research on this issue may be that although rehearsal exerts considerable influence on the magnitude of the primacy effect, other factors may be involved in its formation as well.

The presence of a primacy effect, even a small one, in the absence of rehearsal would be inconsistent with the ratio rule, which predicts a monotonically increasing serial position curve when rehearsal is equated or eliminated. The purpose of the first experiment was to more definitively answer the question of whether a primacy effect would be obtained when the items in a list cannot be rehearsed. The method employed was rapid word presentation. Earlier studies employing rapid presentation either required subjects to recall items in the order in which they were presented (e.g., Crowder, 1970) or included no procedures to ensure that subjects attended to the list items as they were presented (e.g., Murdock \& Walker, 1969). Requiring ordered (instead of free) recall may favor the production of a primacy effect (Dalezman, 1977). Further, unless some measures are taken to ensure attention to each of the rapidly presented items, subjects may ignore later items while surreptitiously rehearsing earlier ones. To control for the possibility of surreptitious rehearsal, subjects in Experiment 1 were required to read the list items aloud as they were presented at a rate of two items per second. This rehearsalpreventing procedure differs from more commonly used methods (e.g., solving simple arithmetic problems) in that it does not introduce extraneous activities into the recall task. Indeed, throughout these experiments, the "distractor" employed to defeat rehearsal was the overt reading or rehearsal of other to-be-remembered words.

\section{Method}

Subjects. Subjects were 18 undergraduates of Emory University who were enrolled in an introductory psychology course. Participation in the experiment satisfied a course requirement.

Materials and design. Sixteen lists of 15 words each were constructed from a pool of 363 high-frequency nouns drawn from Thorndike and Lorge (1944). The words were randomly assigned to 4 practice lists and 12 experimental lists. Within each list, three sets of five words were assigned across subjects equally often to different thirds of the list.

The lists were presented visually on a computer terminal, and subjects were instructed to read each word aloud as it was displayed. Half the lists were presented at a rate of two items per second and half at a rate of two items per $5 \mathrm{~s}$. Presentation rate was a blocked within-subjects variable, with half the subjects receiving the fast rate first and the slow rate second, and the other half receiving the reverse 
order. Because the lists were presented in a constant order, each list was studied under the two rate conditions equally often. Immediately after the presentation of the last word, a tone sounded indicating the beginning of a 60 -s written recall period. Three subjects were randomly assigned to each of the six between-subjects conditions formed by the factorial combination of the three assignments of words to serial positions and the two presentation rate orders.

Procedure. All subjects were tested individually. After signing a consent form, subjects were informed that they would be viewing lists of words on the screen that they would be asked to recall. They were further instructed to read the words aloud and were informed that their responses would be tape recorded. Prior to the experimental trials, each subject received four practice trials--two at the slow rate and two at the fast rate. At the end of the experiment, subjects were asked whether they were able to silently rehearse any of the words during list presentation.

\section{Results and Discussion}

Tape recordings from the fast condition revealed that all subjects were able to read the list words without a great deal of difficulty. Although some subjects had difficulty rea 'ing the practice lists, none had average error rates of greater $t$ in one item per list during the experimental trials. Most subjc ts (15) had no errors. In addition, all subjects reported that whs the list words were presented rapidly, they did not rehe any of the items.

Figure 1 shows the proportion of words recalled as a function of serial position in both the fast and slow conditions. The slow condition produced a robust primacy effect, with the proportion recalled declining rather precipitously over the first three serial positions. The fast condition also produced a primacy effect, but one that was much less pronounced, with the proportion recalled declining gradually over the first four serial positions. Moreover, the absolute level of recall was lower in the fast condition over the first two thirds of the list. The recency effects from the two conditions were quite similar and extended over the last six serial positions.

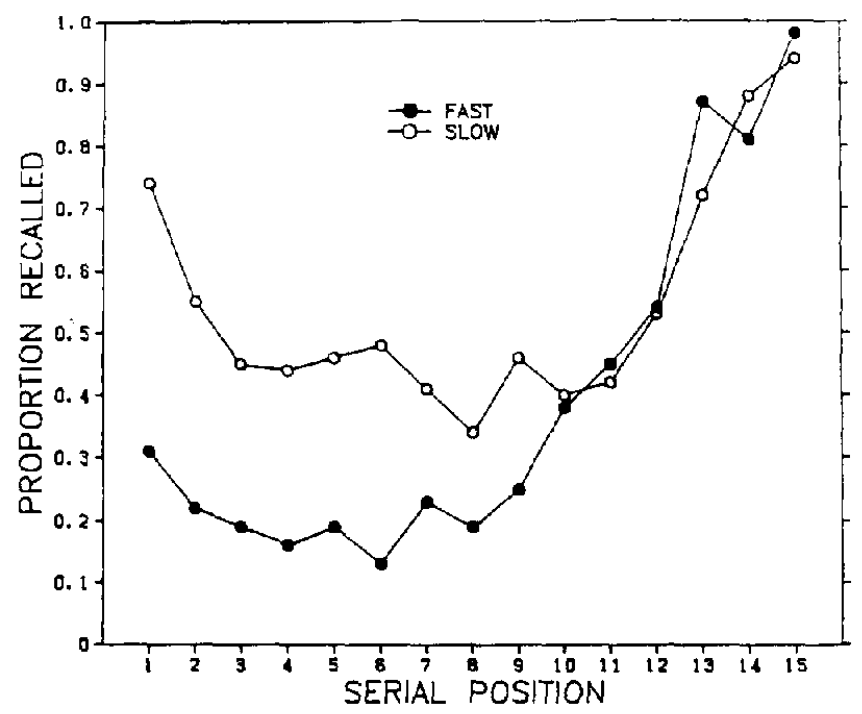

Figure 1. Proportion of words recalled as a function of serial position for the fast and slow conditions of Experiment 1.
The $\alpha$ level for all statistical tests was .05 . As expected, the average number of words recalled in the slow condition $(M$ $=8.22)$ significantly exceeded that of the fast condition $(M=$ 5.92), $F(1,17)=62.00, M S_{\mathrm{c}}=1.85$, and the effect of serial position was highly significant, $F(14,238)=51.19, M S_{\mathrm{e}}=$ 1.25. The interaction between condition and serial position was also significant, $F(14,238)=8.74, M S_{\mathrm{e}}=1.07$.

Because of its theoretical significance, the apparent primacy effect from the fast condition was subjected to further statistical analysis. Specifically, polynomial trend analyses over the first 5 and over the entire 15 serial positions were conducted. The first analysis revealed a significant linear trend over Serial Positions $1-5, F(1,68)=5.58, M S_{\mathrm{v}}=1.08$, with a slope of -0.031 . No other trends covering the first five positions were significant. This result suggests that the primacy effect from the fast condition was not due to chance. A trend analysis over all 15 serial positions revealed a significant linear trend, $F(1,238)=425.37$, and a significant quadratic trend, $F(1$, $238)=175.04, M S_{\mathrm{e}}=1.18$, over the entire 15 serial positions. The quadratic trend captures the bowed appearance of the curve resulting from the presence of both a primacy and a recency effect.

The present findings contrast with the prevailing view that the primacy effect is exclusively a rehearsal phenomenon (Crowder, 1976; Glenberg, 1984). Obviously, rehearsal is a di minant force in the production of the primacy effect as shown by the comparison of the serial position curves from the fast and slow conditions (Figure 1). However, even when subjects do not rehearse, the initial items tend to be somewhat more readily recalled than the middle items.

With regard to the two functional principles considered earlier, the data from Experiment 1 conflict with the ratio rule which holds that, in the absence of rehearsal, the probability of recall is determined by IPI/RI. That ratio is smallest for the initial items of a list and largest for the terminal items. Therefore, rather than exhibiting a primacy effect, the serial position curve should exhibit a monotonic increase in the probability of recall as a function of serial position. In other words, a "negative" primacy effect, if anything, should have been observed.

An obvious way to reconcile the present findings with the ratio rule is to assume that despite their reports to the contrary, the subjects in Experiment 1 were able to devote some rehearsal to the initial items in the fast condition. Indeed, that possibility cannot be ruled out entirely. Assuming their reports were accurate, however, the disputed ratio rule may nevertheless provide a clue to the observed primacy effect. Early accounts of serial position effects (e.g., Murdock, 1960) assumed that items at either end of a list tend to be more easily recalled because they are more distinctive than the middle items. An item is distinctive to the extent that it contrasts with or "stands out" from its surrounding environment. If the surrounding environment is assumed to include surrounding temporal events, then the numerator of the ratio rule, IPI, can be regarded as a rough index of stimulus distinctiveness. That is, the more an item is separated in time from the presentation of other items (i.e., the larger the IPI), the more it contrasts with its surrounding temporal environment and the more distinctive it becomes. 
Considered in this way, the IPI represents a very global measure of stimulus distinctiveness that may not accurately apply to the individual items of a list. The first item of a list, for example, is separated from the sccond item by an amount, IPI, but is preceded by a much longer period of time during which no other items are presented. Thus, the first item may contrast with the surrounding temporal environment to a greater extent than later items. A similar view of temporal contrast can be applied to the last item of a list.

Although this account is reminiscent of traditional theories of retroactive and proactive interference, it differs from an interference account in its emphasis on temporal variables. Consider, for example, the presentation of a list of 15 items in which a long pause is introduced after every fifth word. According to the present view of temporal contrast, the distinctiveness of the first and last item of each five-item sublist should be enhanced compared with the distinctiveness of the middle items. That is, the first item of each sublist is preceded by a relatively long period of time during which no other items are presented, thereby enhancing contrast with the "background" temporal environment. Similarly, the last item of each sublist is followed by a relatively long period of time during which no other items are presented, thereby enhancing the temporal contrast associated with those items. Under these conditions, one might expect to observe primacy and recency effects associated with each sublist of five items.

\section{Experiment 2}

In the second experiment, subjects were presented with lists of 15 words in the manner described above. Five words were presented rapidly, followed by a 15 -s pause, followed by the rapid presentation of 5 more words, followed by a second 15 $s$ pause, followed by the rapid presentation of the last 5 words. Immediately following the presentation of the last item, the recall period began. According to the temporal contrast account proposed above, each sublist should exhibit both a primacy and a recency effect.

The introduction of delay intervals within a list in order to manipulate temporal contrast also enables subjects to differentially rchearse list items. Thus, any sublist primacy and recency effects could occur due to extra rehearsal of the first or last few items of each sublist (e.g., Gianutsos, 1972). To control for this possibility, subjects were instructed to rehearse out loud only the most recently presented set of five words during each 15-s delay period. It was assumed that the task of rehearsing five words would be of sufficient difficulty to prevent surreptitious rehearsal of any other words in the list. Moreover, the procedure should roughly equate the amount and distribution of rehearsal received by words in the first two sets.

At least two earlier studies (Brodie \& Prytulak, 1975; Fischler, Rundus, \& Atkinson, 1970) have attempted to equate rehearsal by instructing subjects to rehearse aloud only the most recently presented item. In both experiments, a primacy effect was observed (contrary to a pure rehearsal account of the primacy effect). However, Brodie and Prytulak (1975) also reported that their subjects admitted to surreptitiously rehearsing items beyond their nominal serial positions. In the following experiment, this possibility seems more remote. Indeed, the required overt rehearsal of one set of to-beremembered words to prevent rehearsal of another set seemed to be the most effective "distractor" possible (cf. Baddely \& Hitch, 1974).

\section{Method}

Subjects. The 27 subjects who participated in this experiment were drawn from the same source as the preceding experiment.

Materials and design. The lists used in Experiment 1 were again used here. The words from each list were presented on a computer screen in three sets of five words. Within each set, the words were presented at a rate of two items per second, and the first two sets were each followed by a 15-s pause. The recall period began immediately after the fifth word of the last set. The beginning of each delay period was signaled by a row of asterisks on the screen, and the beginning of the 60 -s recall period was signaled by a tone.

The design of this experiment is based on the procedure employed by Fischler et al. (1970). Each subject was tested under three rehearsal conditions. In the main condition (fixed), subjects were instructed to read each word aloud as it was presented and to continue repeating those words aloud during the delay. Subjects were instructed to rehearse only the words from the most recently presented set as quickly as they could. In a second condition (overt), subjects were instructed to read each word as it was presented and to rehearse aloud any words that they happened to be thinking about during each delay. In other words, no restrictions were placed on rehearsal. In the third condition (covert), subjects were instructed to read the words aloud as they werc presented, but to rehearse silently. Thus, both the overt and covert trials permitted free rehearsal.

The overt and covert free-rehearsal conditions were included to evaluate any effects of requiring overt rehearsal per se. Although most experiments have found little, if any, difference between covert and overt rehearsal conditions (e.g., Horton, 1976; Murdock \& Metcalfe, 1978; Roenker, 1974), some have found slight differences (e.g., Fischler et al., 1970; Kellas, McCauley, \& McFarland, 1975). Therefore, both types of rehearsal conditions were included as controls.

The 12 experimental lists were presented in a constant order. Rehearsal condition changed after each list was presented according to one of three orders so that each list was studied under the three rehearsal conditions equally often. Three subjects were randomly assigned to each of the nine between-subjects conditions formed by the factorial combination of three assignments of sets of words to serial positions (cf. Experiment 1) and thrce orders of rehearsal conditions.

Procedure. All subjects were tested individually. After signing a consent form, subjects were informed that they would be seeing lists of words that they would be asked to recall. They were also told that the lists would consist of three sets of five words each, and the three rehearsal conditions were described. Subjects received three practice trials (onc for each condition) prior to the 12 experimental trials. Overt rehearsals from the fixed condition were tape recorded for subsequent analysis.

\section{Results and Discussion}

All but 2 subjects reported that the effort to rehearse the second set of five words effectively prevented them from rehearsing words from the first set in the fixed condition. The 2 subjects who reported that they were able to rehearse words from Set One following the presentation of Set Two were excluded and replaced. Tape recordings from the fixed con- 
dition revealed that intrusions from set one during rehearsal of words from set two were extremely rare, occurring on less than $1 \%$ of list presentations.

Figure 2 shows that proportion of words recalled as a function of serial position for the fixed (F), overt $(\mathrm{O})$, and covert (C) conditions. With the possible exception of the first set of five words in Condition $\mathrm{O}$, serial position effects consisting of a primacy effect alone or both primacy and recency effects are evident in the sublists from all conditions.

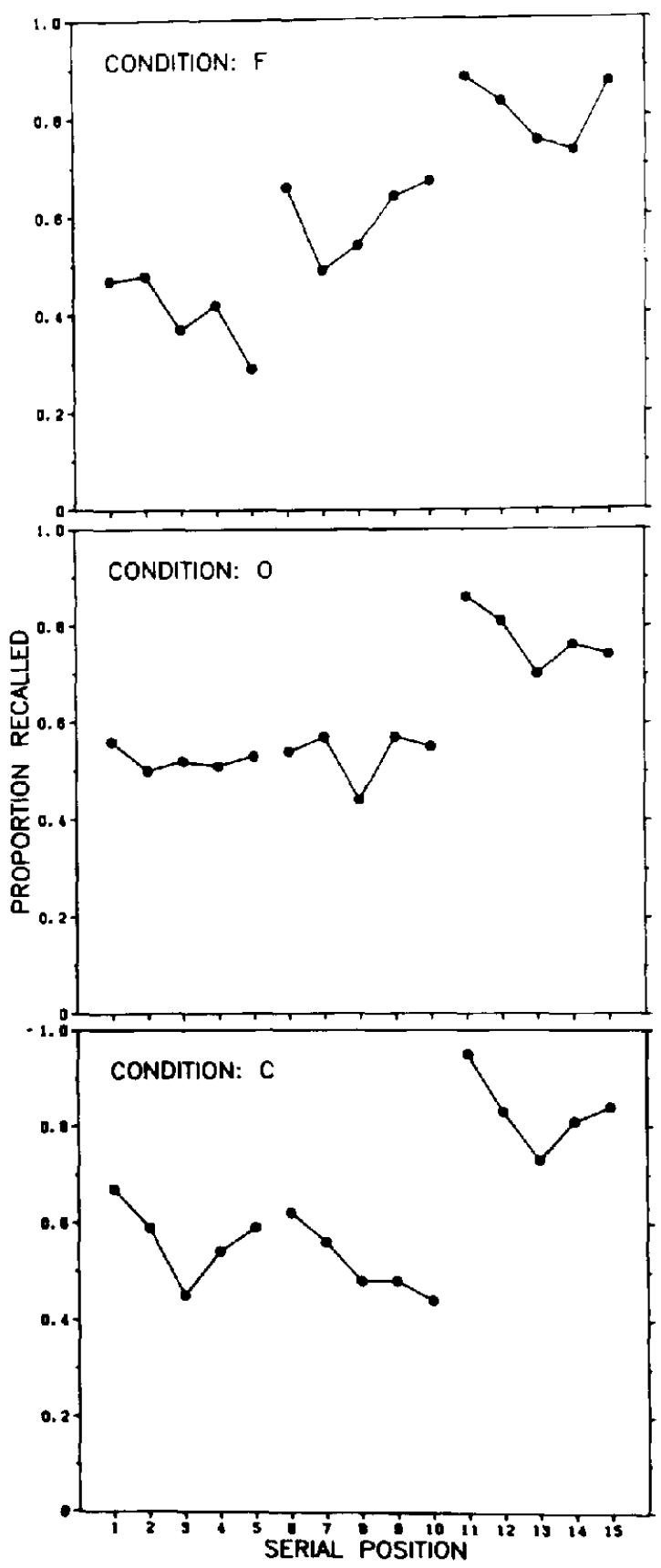

Figure 2. Proportion of words recalled as a function of serial position for the fixed (Condition F), overt (Condition O), and covert (Condition C) conditions of Experiment 2.
Table 1

Mean Number of Overt Rehearsals per Word in Condition F

\begin{tabular}{ccc}
\hline $\begin{array}{c}\text { Serial position } \\
\text { (within set) }\end{array}$ & Set 1 & Set 2 \\
\hline 1 & 4.96 & 4.14 \\
2 & 4.82 & 3.87 \\
3 & 4.76 & 3.82 \\
4 & 4.69 & 4.05 \\
5 & 4.82 & 4.19 \\
\hline
\end{tabular}

In Condition $\mathrm{F}$, the most important from a theoretical standpoint, the first set produced a primacy effect, while the second and third sets yielded both primacy and recency effects. To verify these apparent sublist serial position effects, the results from each set of five words in Condition $F$ were subjected to polynomial trend analysis. The first set of five words produced a significant linear trend, $F(1,104)=9.58$, $M S_{\mathrm{c}}=0.78$, indicating the existence of a primacy effect only. Sets 2 and 3 exhibited significant quadratic trends only, $F(1$, $104)=7.26, M S_{\mathrm{e}}=0.80$, and $F(1,104)=10.35, M S_{\mathrm{e}}=0.56$, respectively, thus confirming the presence of primacy and recency effects within each sublist.

One goal of Condition $F$ was to ensure that the items within a set would receive the same number of rehearsals. Table 1 shows the number of rehearsals received by each word in the first two sets of Condition $F$ (the words in the third set were not rehearsed). In the first set, the average number of rehearsals per word ranged from 4.69 to 4.96 , and the differences between them did not approach significance, $F(4,104)=$ $1.52, M S_{c}=2.82, p>.10$. In the second set, the average number of rehearsals per word ranged from 3.82 to 4.19 , and again the differences were not significant, $F(4,104)=1.86$, $M S_{\mathrm{c}}=6.01, p>.10$. It is interesting to note, however, that when subjects occasionally forgot one word in the set during rehearsal, it tended to be one of the middle items rather than one of the end items. Nevertheless, these differences appear to be too slight to have caused the scrial position effects evident in Figure 2. Of course, this is especially true of the items in the third set of all three conditions, which were simply read once immediately prior to the beginning of the recall period.

Conditions $\mathrm{O}$ and $\mathrm{C}$ were included to gauge any unexpected effects resulting from requiring subjects to rehearse aloud. An analysis of variance was conducted on the data from these two conditions with condition ( $\mathrm{O}$ and $\mathrm{C}$ ), set (first, second, and third), and serial position within set (one through five) as within-subjects factors. This analysis revealed a main effect of set, $F(2,52)=29.90, M S_{\mathrm{e}}=3.61$, and serial position within set, $F(4,104)=8.69, M S_{\mathrm{t}}=0.79$. The main effect of condition and all interactions involving the condition factor were not significant. These results are in agreement with earlier experiments that have found no difference between overt and silent rehearsal conditions (e.g., Horton, 1976; Murdock \& Metcalfe, 1978; Roenker, 1974).

The results of Experiment 2 support the notion that the distinctiveness of any item in a list can be enhanced by increasing the degree to which it contrasts with its surrounding temporal environment. When that environment is filled with 
the presentation of other items, contrast is relatively low, and delayed recall is less likely. When the surrounding temporal environment is free of other items, contrast is sharpened, thereby enhancing the chances of delayed recall. To some extent, the present findings should not be surprising since the well-known von Restorff effect (von Restorff, 1933) occurs because an individual item contrasts along a perceptual dimension from other items in the immediate temporal vicinity. Nevertheless, Experiment 2 appears to offer the first definitive demonstration that temporal contrast can be manipulated to yield a primacy effect and, somewhat less reliably, a recency effect even when rehearsal is controlled. These results lend credibility to the notion that the primacy effect of single-trial free recall is not exclusively a rehearsal phenomenon.

The sublists in the present experiment were blocked by means of temporal separation, but other studies using different blocking methods have also reported sublist serial position effects. For example, Murdock and Walker (1969) presented subjects with four blocks of five items alternating between visual and auditory modes. The modality-specific sublists in this experiment produced clear primacy and recency effects. Roediger and Schmidt (1980) presented subjects with lists in which the items were blocked by category membership. Again, the resulting within-category sublists exhibited robust primacy effects, but clear evidence of a recency effect was not obtained. The sublist serial position effects in these experiments may have resulted from the temporal isolation of perceptually and conceptually similar items. According to this interpretation, for example, the more temporally remote a preceding visual item is, the more likely a visual sublist is to exhibit a primacy effect. Although speculative, this analysis suggests one approach to unifying the results of studies that use a variety of blocking procedures.

Rehearsal may not be required to produce a primacy effect, but it obviously exerts considerable influence on the form of a typical serial position curve. The precise way in which rehearsal produces that effect is still not very well understood. Earlier studies have demonstrated that the number of rehearsals per se received by the initial items of a list does not account for the primacy effect but that either the number of distributed rehearsals (Modigliani, 1980) or the type or rehearsal (Craik \& Watkins, 1973) received by the initial items is the critical factor. The third experiment was conducted to test these accounts, as well as a third possibility not previously considered. In addition, the design of Experiment 3 permitted a partial replication of the results from the fixed condition in Experiment 2.

\section{Experiment 3}

Craik (1970) introduced a now well-known procedural innovation in which, at the end of a single-trial free recall session, subjects are asked to remember as many of the words as they can from all of the lists they studied earlier in the session. This procedure was designed to exploit a well-established finding that the time devoted to rehearsal of an item in a list decreases as a function of its serial position (Rundus, 1971). Craik (1970) reasoned that if rehearsal is an important antecedent of delayed recall, then in an unexpected final free recall (FFR) period, subjects should be most likely to remember the items that were originally presented in the initial serial positions of a list and least likely to remember the items that were originally presented in the terminal serial positions of a list. Indeed, the results of Craik's experiment confirmed that prediction.

In a later experiment, Craik and Watkins (1973) permitted subjects to rehearse the last four items of several 12-item lists for an extra $20 \mathrm{~s}$ prior to initiating each recall period. Despite this extra rehearsal, the probability of recall for the last four items of each list was not enhanced even slightly during an unexpected final free-recall period. To account for this surprising result, they suggested that the type or rehearsal typically applied to the initial items of a list differs from the type of rehearsal typically applied to the terminal items. Because the initial items can be rehearsed only temporarily (due to the incoming flow of subsequent items), they must be "deeply" processed by means of elaborative rehearsal if they are to be successfully recalled after the entire list is presented. By contrast, the terminal items can be rehearsed indefinitely (i.e., up to the beginning of the recall period) and therefore require only "shallow" processing accomplished by means of maintenance rehearsal. The latter form of rehcarsal is assumed to have no cumulative effect on the richness or strength of a memory trace.

Direct evidence that subjects employ different rehearsal strategies as a function of serial position has not been forthcoming, in part because of inherent difficulties in independently measuring depth of processing (Baddeley, 1978; Nelson, 1977). An alternative explanation for the apparent difference in rehearsal effectiveness for the initial and terminal items of a list is based on the idea of temporal distribution. As indicated earlier, Modigliani $(1976,1980)$ showed that distributed rehearsals (i.e., rehearsals separated by at least a few seconds) exert a much greater strengthening effect than do immediate rehearsals (i.e., rehearsals occurring in rapid succession). It may be, for example, that the initial items of a list tend to receive distributed rehearsals while the terminal items tend to receive less effective immediate rehearsals. Modigliani and Hedges (1987) have recently presented evidence to support this hypothesis.

Still another possibility is that, independent of the type or distribution of rehearsal, the memory context influences rehearsal effectiveness. That is, in the context of only a few tobe-remembered words (i.c., at the beginning of the list), rehearsal may be more effective than in the context of many to-be-remembered words (i.e., at the end of the list). This hypothesis was derived, in part, from an item-repetition experiment conducted by Underwood (1969). A typical finding of item repetition experiments is that spaced repetitions increase the probability of recall far more than do massed repetitions (Melton, 1970). Underwood, however, found that massed repetitions of an item occurring near the beginning of a list unexpectedly enhanced later recall. Indeed, the effect was greater than that resulting from spaced repetitions of an item distributed throughout the list. One interpretation of this finding is that the strengthening effect of repetition (and, by analogy, rehearsal) decreases as a function of the context of to-be-remembered items. 
Experiment 3 was designed to test the three principles discussed above relating to the type, distribution, or context of rehearsal. The procedure used in this experiment is a modification of Craik and Watkins' (1973) FFR experiment. Subjects were exposed to four kinds of lists: one allowing extra rehearsal of the beginning five items (Condition $B$ ), one allowing extra rehearsal of the middle five items (Condition $M$ ), one allowing extra rehearsal of the end five items (Condition E), and one permitting no rehearsal followed by immediate recall (Condition I). Unlike the Craik and Watkins (1973) experiment, this procedure was designed to equate the amount of rehearsal received by different sections of a list and, for the first time, to measure the relative effectiveness of rehearsal of the middle items in a quantitative fashion.

If subjects alter the type of rehearsal employed on the basis of whether or not they can rehearse an item up to the moment of recall, then rehearsed items from Conditions $B$ and $M$ (which cannot be rehearsed to the moment of recall) should both be more readily recalled at the end of the session than the rehearsed items from Condition $\mathrm{E}$ (which can be rehearsed up to the moment of recall). Moreover, for all three conditions, subjects were expected to produce the same rate and distribution of rehearsal. Thus, if rehearsal distribution is the critical variable, then the effectiveness of rehearsal should not vary as a function of list position. Finally, if the rehearsal context is the governing variable, then the effectiveness of rehearsal should be greatest for items in Condition B, somewhat less for items in Condition $\mathrm{M}$, and least for items in Condition E.

\section{Method}

Subjects. The 36 subjects who participated in this experiment were drawn from the same source used in the preceding experiments.

Materials and design. The same lists that were used before were used in this experiment. List words were presented at a rate of two items per second, with the exception that after the 5th (Condition B), 10 th (Condition $\mathrm{M}$ ), or 15 th word (Condition $\mathrm{E}$ ), a 15-s delay was provided to allow extra rehearsal of the immediately preceding 5 words. In each case, the to-be-rehcarsed words were presented in uppercase letters while the remainder were presented in lower case. The beginning of a delay period was signaled by a row of asterisks on the screen, and the beginning of the recall period following list presentation was signaled by a tone. A control condition was included in which no delay period was presented, and recall began immediately after the presentation of the last word (Condition I).

The 12 experimental lists were presented in a constant order. Rehearsal condition changed after each list was presented according to one of four orders in such a way that each list was studied under the four conditions equally often. Three subjects were randomly assigned to each of the 12 between-subjects conditions formed by the factorial combination of three assignments of sets of words to serial position and four presentation orders of conditions.

Procedure. Subjects were tested individually and informed of the various delay conditions. They were instructed to read the items aloud and to overtly rehearse the five words in uppercase letters that immediately preceded the delay. Four practice lists were presented (one for each condition) followed by the 12 experimental lists. After all lists were presented, subjects were engaged in approximately 2 min of conversation, followed by an unexpected final free recall of all of the words from all of the lists. During the conversation period,
Table 2

Mean Number of Overt Rehearsals per Word in Each

Rehearsal Condition

\begin{tabular}{cccc}
\hline $\begin{array}{c}\text { Serial position } \\
\text { (within set) }\end{array}$ & B1 & M2 & E3 \\
\hline 1 & 4.04 & 4.03 & 3.88 \\
2 & 3.93 & 3.92 & 3.66 \\
3 & 3.58 & 3.51 & 3.49 \\
4 & 3.69 & 3.53 & 3.56 \\
5 & 3.71 & 3.58 & 3.63 \\
\hline
\end{tabular}

Note. $\mathrm{B} 1=$ Condition $\mathrm{B}$, Set $1 ; \mathrm{M} 2=$ Condition $\mathrm{M}$, Set $2 ; \mathrm{E} 3=$ Condition F., Set 3

subjects werc asked about any rehearsal strategies they had used during list presentation. The final free-recall period lasted $10 \mathrm{~min}$.

\section{Results and Discussion}

Initial recall. All subjects complied with the rehearsal instructions. Overt repetitions for words not targeted for rehearsal (i.e., those not in uppercase letters) were extremely rare, occurring on less than $1 \%$ of list presentations. Most subjects reported that they did not employ different rehearsal strategies for words in different sections of a list. However, a few subjects said that they attempted to formulate stories or create images for rehearsed words in Conditions B and $\mathrm{M}$ only.

Table 2 shows the number of overt rehearsals each word received in Conditions $\mathrm{B}, \mathrm{M}$, and $\mathrm{E}$. The numbers following each letter in the column headings refer to a specific set of five items in the list condition (e.g., B1 refers to the first set of five items from Condition B). Despite slight differences across sublist serial positions, the amount of rehearsal received by words in different sets was essentially equivalent. The avcrage number of rehearsals received by the first five words of Condition B was 3.79. The average number of rehearsals received by the second five words of Condition $\mathrm{M}$ was 3.71 , and the average number of rehearsals received by the last five words of Condition $\mathrm{E}$ was 3.64. These differences did not approach significance. Because the words were almost invariably rehearsed in the same order in which they were presented, the interrehearsal interval for each item during the 15$\mathrm{s}$ delays was on the order of $4 \mathrm{~s}$.

Figure 3 shows the probability of initial recall plotted as a function of serial position for Conditions $\mathrm{B}, \mathrm{M}$, and $\mathrm{E}$. The results from each condition are plotted separately along with the results from the control condition, Condition I. The figure clearly shows that extra rehearsal of any set of five words increases the probability of initial recall of those words relative to unrehearsed words with similar delays.

Because the experiment is primarily concerned with the effects of rehearsal, an analysis of variance was conducted on the rehearsed items from each experimental condition (B1, $M 2$, and $E 3$ ) versus the corresponding unrehcarsed items from the control condition (I1, I2, and I3). The analysis of variance contained three within-subjects factors: rehearsal condition (rehearsed vs. unrehearsed), set, and serial position within set. The results of that analysis revealed a main effect of rehearsal 
condition, $F(1,35)=375.66, M S_{\mathrm{c}}=1.01$, set $F(2,70)=$ 170.16, $M S_{\mathrm{e}}=0.67$, and serial position within set, $F(4,140)$ $=7.93, M S_{\mathrm{c}}=0.53$. The interactions involving rehearsal condition by set, $F(2,70)=58.48, M S_{\mathrm{e}}=0.60$, rehearsal
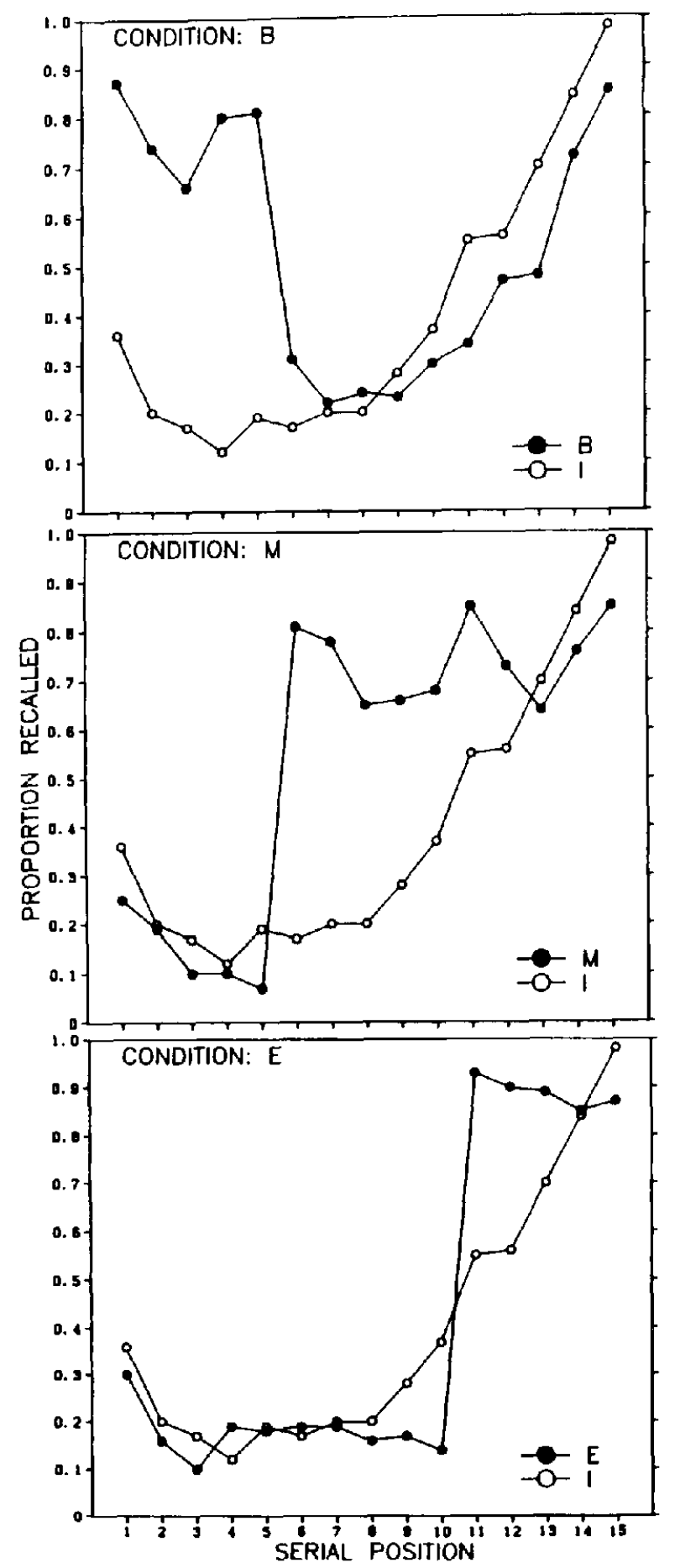

Figure 3. Proportion of words recalled as a function of serial position for beginning (Condition B), middle (Condition M), and end (Condition $\mathrm{E}$ ) rehearsal conditions in immediate recall. (Each graph also depicts the results from the no-rehearsal immediate recall condition [Condition I]). condition by serial position within set, $F(4,140)=9.98, M S_{c}$ $=0.51$, and rehearsal condition by set by serial position within set, $F(8,280)=6.18, M S_{\mathrm{e}}=0.55$, were also significant.

Pairwise contrasts between the rehearsed sets and the corresponding unrehearsed sets (i.e., B1 vs. I1, M2 vs. 12, and E3 vs. 13) were conducted by means of the Bonferroni $t$ statistic to determine the source of the significant rehearsal effect. These analyses revealed that the average number of items recalled from $\mathrm{B} 1(M=3.87)$ significantly exceeded the average number of items recalled from $\mathrm{Il}(M=1.05), t(35)=19.21$, $S E=0.44$; the average number of items recalled from M2 $(M=3.50)$ significantly exceeded the average number of items recalled from $I 2(M=1.22), t(35)=11.99, S E=0.57$; and the average number of items recalled from E3 $(M=4.44)$ significantly exceeded the average number of items recalled from $I 3(M=3.63), t(35)=8.03, S E=0.31$. These results confirm the apparent increase in probability of initial recall for rehearsed items from any set compared with unrehearsed items from corresponding sets.

Pairwise contrasts were also performed between the three rehearsal sets (i.e., B1 vs. M2, B1 vs. E3, and M2 vs. E3). These analyses revealed that the average number of items recalled from E3 significantly exceeded the average number of items recalled from $B 1, t(35)=4.97, S E=0.35$, and from $\mathrm{M} 2, t(35)=6.62, S E=0.43$. The difference between the average number of items recalled from B1 and M2 was not significant, $t(35)=2.44, S E=0.46, p>.05$.

The significant effect involving serial position within set was evidently due to the appearance of several sublist serial position effects similar to those found in Experiment 2. Two sets of five words were temporally isolated from the presentation of the remaining items: B1 (which were also rehearsed) and M3 (which were not rehearsed). As shown in Figure 5, both sets exhibit robust primacy and recency effects, which were confirmed by the presence of significant quadratic trends only, $F(1,140)=11.42, M S_{\mathrm{e}}=0.49$, and $F(1,140)=21.90$, $M S_{\mathrm{c}}=0.42$ for $\mathrm{B} 1$ and $\mathrm{M} 3$, respectively.

The rehearsed items from $M 2$ revealed a primacy effect and a very slight recency effect even though this set was not temporally isolated from the presentation of preceding items. One possibility is that these apparent serial position effects derived, in part, from the perceptual uniqueness associated with the presentation of to-be-rehearsed items in this experiment (cf. Murdock \& Walker, 1969). Trend analysis for this sublist yielded a complicated picture, with significant linear, $F(1,140)=8.47$, quadratic, $F(1,140)=7.95$, and quartic, $F(1,140)=6.09, M S_{\mathrm{c}}=0.54$, trends. The rehearsed items from E3 did not exhibit any apparent serial position effects (possibly because of a ceiling effect), and no trends were significant. Finally, the whole-list primacy effect of Condition I replicates the effect found for the fast condition in Experiment 1 . The apparent primacy effect was confirmed by the presence of significant linear, $F(1,490)=389.63$, and quadratic, $F(1,490)=164.15, M S_{\mathrm{c}}=0.58$, trends.

Final recall. Figure 4 shows the probability of final recall as a function of serial position for Conditions B, M, and E. The results from the control condition (I) are once again plotted on each graph for comparative purposes. The figure shows that the rehearsed words from Conditions $B$ and $M$ were more likely to be recalled than the corresponding words 

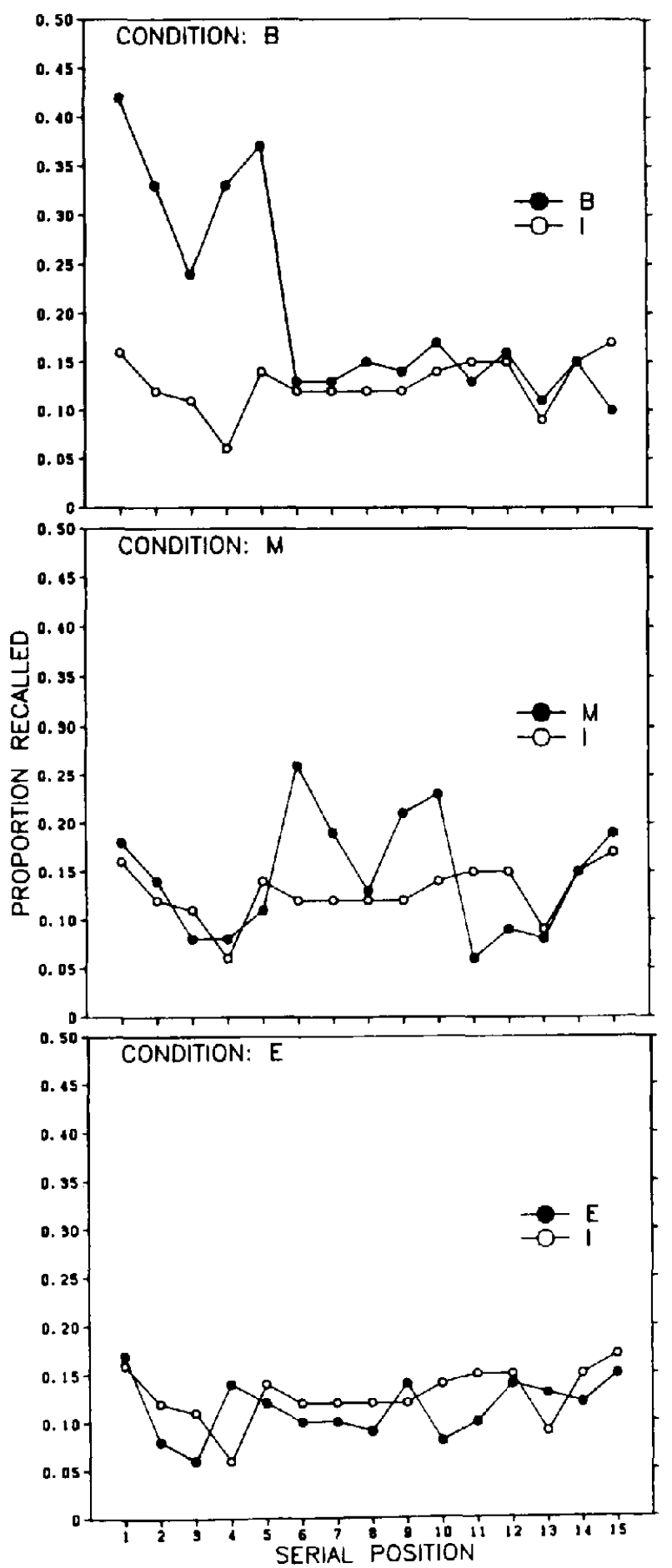

Figure 4. Proportion of words recalled as a function of serial position for beginning (Condition B), middle (Condition M), and end (Condition E) rehearsal conditions in final free recall. (Each graph also depicts the final free recall results from the no-rehearsal immediate recall condition [Condition I]).

from Condition I. However, in agreement with earlier findings, the rehearsed words from Condition $\mathrm{E}$ were apparently no more likely to be recalled than the corresponding words from Condition I (cf. Craik \& Watkins, 1973).
Once again, an analysis of variance was conducted on the items from the three rehearsal sets (B1, M2, and E3) versus the corresponding items from the unrehearsed list (I1, I2, and I3). The analysis revealed a main effect for rehearsal, $F(1,35)$ $=29.28, M S_{\mathrm{c}}=0.77$, set, $F(2,70)=13.35, M S_{\mathrm{e}}=0.55$, and for serial position within set, $F(4,140)=3.75, M S_{\mathrm{e}}=0.36$. The interaction between rehearsal condition and set was also significant, $F(2,70)=15.98, M S_{\mathrm{e}}=0.71$.

To examine the source of these significant effects, pairwise contrasts were again performed by means of the Bonferroni $t$ statistic. The first set of comparisons contrasted the rehearsed items with the corresponding items from the control condition (i.e., B1 vs. I1, M2 vs. I2, and E3 vs. I3). This analysis revealed that the average number of items recalled from B $1(M=1.69)$ significantly exceeded the average number of items recalled from Il $(M=0.58), t(35)=6.10, S E=0.55$. The average number of items recalled from M2 $(M=1.02)$ exceeded the average number of items recalled from $\mathrm{I} 2(M=0.62)$, but the effect was only marginally significant according to the conservative Bonferroni criterion, $t(35)=2.62, S E=0.46, p=$ .076 . The average number of items recalled from E3 ( $M=$ 0.64 ) was actually slightly fewer than the average number of items from I3 $(M=0.70)$, but the difference was not significant.

Additional contrasts were performed involving only the rehearsed items (i.e., B1 vs. M2, B1 vs. E3, and $\mathrm{M} 2$ vs. E3). This analysis revealed that the average number of words recalled from $B 1$ significantly exceeded the average number of words recalled from $\mathrm{M} 2, \ell(35)=3.53, S E=0.57$, and from $\mathrm{E} 3, t(35)=6.59, S E=0.48$. Further, the average number of words recalled from M2 significantly exceeded the average number of words recalled from $E 3, t(35)=2.92, S E=0.39$.

Figure 5 shows the probability of recall and number of rehearsals (including the initial reading of the word) for items from B1, M2, and E3. The figure clearly summarizes the conclusions based upon statistical analysis. Although the

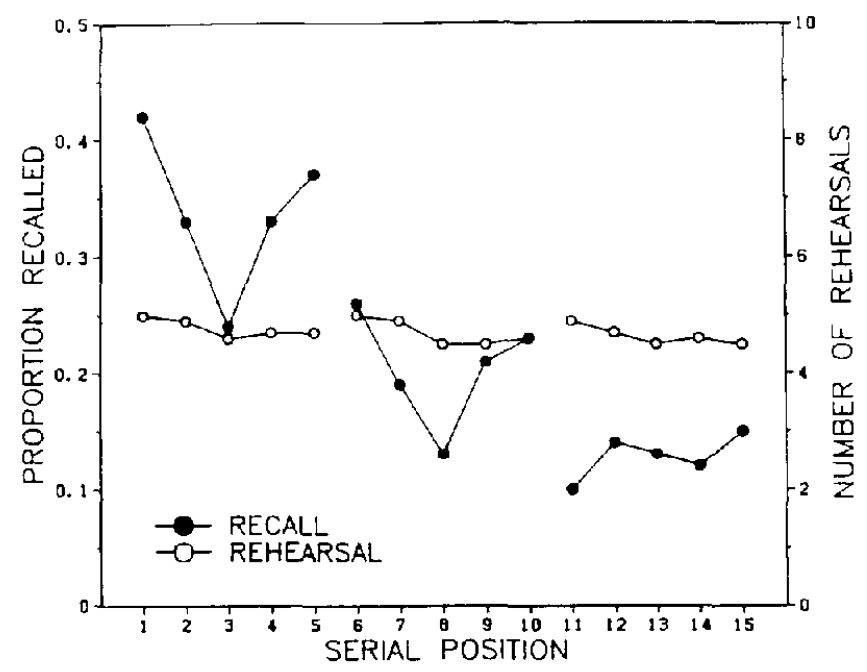

Figure 5. Proportion of words recalled and number of rehearsals received as a function of serial position for the rehearsed words from the beginning, middle, and end rehearsal conditions in final free recall. 
number of rehearsals received by each word is roughly constant, the probability of final recall declines from B1 to E3.

The distribution of rehearsal for the items in sets B1, M2, and E3 was roughly equivalent because the interrehearsal interval in each case was approximately $4 \mathrm{~s}$. Moreover, because Modigliani (1976) found that the maximum strengthening effect of rehearsal occurs over delays of only a few seconds, rehearsal should have been quite effective in all conditions. Therefore, the present results are not accommodated by a rehearsal distribution analysis.

On the other hand, it has also been argued that initial recall itself may be construed as an extra rehearsal that can facilitate FFR performance. During initial recall, the rehearsed items from Condition B were recalled over a delay of at least $5 \mathrm{~s}$ (the time taken to present the final 10 words). The rehearsed items from Condition $M$ were initially recalled over a delay of at least $2.5 \mathrm{~s}$ (the time taken to present the final 5 words), and the rehearsed items from Condition $\mathrm{E}$ were initially recalled over a 0 -s delay. Thus, the items from $\mathrm{B} 1$ and $\mathrm{M} 2$ may have received one additional distributed rehearsal while the items from E3 received an extra immediate rehearsal.

As Modigliani (1976) has acknowledged, strengthening effects of initial recall are difficult to separate from simple item selection effects. That is, for idiosyncratic reasons, certain items will be more memorable for a subject than other items. Such items are likely to be recalled over fairly long delays in initial recall and to be recalled again over even longer delays in FFR, giving the appearance of an initial strengthening effect. Nevertheless, the possibility of strengthening due to initial recall should be evaluated as a possible alternative interpretation of the present findings.

A measure of the differential strengthening effect attributable to initial recall in this experiment may be obtained by examining the conditional probability of final recall for the items from Condition I. The conditional probability of final recall is the probability of final recall, given that the word was initially recalled. For the items from $\mathrm{I} 1, \mathrm{I} 2$, and $\mathrm{I} 3$, the delays associated with initial recall match the delays associated with items from B1, M2, and E3.

The conditional probability of final recall for items from $\mathrm{I} 1, \mathrm{I} 2$, and $\mathrm{I} 3$ were $0.51,0.47$, and 0.20 , respectively. Thus, the likelihood that an initially recalled word from the first five or second five serial positions would be rocalled again in FFR was about $50 \%$ in Condition I. For words in the last five serial positions, only about $20 \%$ of those initially recalled were again recalled in FFR. Thus, any strengthening effect of initial recall for B1 and M2 items should have been roughly the same. The above findings are in agreement with Modigliani's $(1976,1980)$ results which suggest that the maximum strengthening effect of delayed recall is reached after only a few seconds (in this case about $2.5 \mathrm{~s}$ ). This result also rules out a delayed recall interpretation of the results presented in Figure 5.

An explanation appealing to different types of rehearsal also does not easily accommodate these findings. If subjects employ an effective form of rehearsal for words that cannot be rehearsed up to the moment of recall (namely, B1 and M2 words), and an ineffective form of rehearsal for words that can be rehearsed up to the moment of recall (namely E3 words), then the final pattern of results should have been BI
$=\mathrm{M} 2>\mathrm{E} 3$. It should be added that very few subjects admitted to changing rehearsal strategies as a function of set position (cf. Shaughnessy, 1981).

The rehearsal context hypothesis, proposed earlier, assumes that the effectiveness of rehearsal on delayed recall declines as a function of the context of to-be-remembered items. In the context of only a few to-be-remembered items, rehearsal should significantly increase the probability of delayed recall. In the context of many to-be-remembered items, rehearsal should be less effective. The results of Experiment 3 support this hypothesis. Despite apparently identical rehearsal activity, the effect on delayed recall declined as a function of the memory load at the time of rehearsal. This principle may help to account for the surprisingly strong effect of massed item repetition for words situated at the beginning of a list (Underwood, 1969), as well as the remarkable persistence of the primacy effect even when efforts are undertaken to equate the amount of rehearsal received by the individual items (Brodie \& Prytulak, 1975; Fischler et al., 1970).

Finally, sublist serial position effects are strikingly apparent in Figure 5. The items from B1 and M2 exhibit very pronounced primacy and recency effects (even more pronounced than in initial recall) that were confirmed by significant quadratic trends only, $F(1,140)=9.45, M S_{\mathrm{c}}=0.43$, and $F(1,140)$ $=5.82, M S_{e}=0.41$, respectively. This result was unexpected, and it is not clear why these effects would become more pronounced with the passage of time. The items from E3 that exhibited no apparent serial position effects in initial recall also showed no such effects in final recall.

\section{General Discussion}

The present series of experiments was intended to advance the functional analysis of single-trial free recall. This approach is characterized by the search for lawful empirical relations between variables under the control of the experimenter and a behavioral measure of interest. The ongoing objective of a functional analysis is to subsume disparate empirical phenomena under ever broadening laws of behavior. While remaining silent on the question of mechanism, a functional analysis may facilitate the development of mechanistic explanations by lending cohesion to an otherwise disconnected array of findings. Two empirical principles-one an item-position account and the other a rehearsal account-were the subject of the present investigation.

\section{Item Position Accounts}

The first two experiments were concerned with a generally accepted empirical principle of free recall known as the ratio rule (Crowder, 1976). This principle holds that when the effects of rehearsal are controlled, the probability of delayed recall is a function of the ratio, IPI/RI. Because the value of RI decreases as the serial position of an item increases, the ratio rule predicts that in the absence of rehearsal, the serial position curve should be characterized by a recency effect only. In contrast to that prediction, Experiment 1 demonstrated that when words are presented too rapidly to be rehearsed, a small but reliable primacy effect was nevertheless obtained. 
To reconcile this finding with the ratio rule, it was suggested that the numerator (IPI) might be construed as a crude index of temporal distinctiveness (i.e., the extent to which an item contrasts with its surrounding temporal environment). The shorter the IPI, the less distinctive the individual stimuli become because of the close proximity of other, similar items. As an index of stimulus distinctiveness, two problems with the IPI can be immediately identified. First, it offers no account of the unique environments preceding and following the first and last items of a list, respectively (or preceding and following sublists when items are not presented in a periodic fashion). Second, the measure offers no account of the cumulative effect of each item on the distinctiveness of every other item in a list. The distinctiveness of a stimulus may depend upon more than its proximity to immediately adjacent stimuli alone (cf. Murdock, 1960).

Considered in this way, then, the IPI is not a very satisfying measure, and it may be possible to improve upon it while retaining the basic properties of the ratio rule. Murdock (1960) proposed a distinctiveness account based on the Weber-Fechner law, which maintained that an item was distinctive to the extent that the logarithm of its energy was large compared with that of all other items in a series. For a stimulus series consisting of sounds varying in intensity, energy can be objectively quantified. For a list of words, however, the relevant dimension is less clear. In Murdock's account, the serial position of an item was taken as a measure of its subjective energy. Bower (1971) criticized this theory partly because it did not define as distinctive what must be so. In Murdock's account, the middle item of a series is always determined to be the least distinctive item. Thus, Bower argued, in a series of tones consisting of $3.9,4.0,4.1,45,84.9,85.0$, and 85.1 $\mathrm{dB}$, the middle tone should be the least distinctive. In fact, the 45-dB tone is likely to be the most distinctive.

A similar argument can be raised with respect to the temporal pattern of item presentation in a free recall experiment. If, for example, one item of a list (say, the middle item) is preceded and followed by an especially long interval during which no other items are presented, then the distinctiveness of that item is likely to be enhanced. The results of Experiment 2 confirmed that an item is more likely to be recalled when its surrounding temporal environment is free of the presentation of other items.

One way to follow Murdock's (1960) basic approach to relative stimulus distinctiveness while accommodating the possible effects of temporal variables is to assume that the relevant measure of temporal contrast is the average temporal distance between an item and all other items in a list, not simply the average distance from an adjacent item. When placed into the numerator of the ratio rule, this measure would behave in a manner very similar to the IPI but would allow for the differential specification of distinctiveness for individual items in a list. Thus, as the IPI increases, the average temporal distance between an item and all other items in a list increases as well. More important, for items at either end of a list (or sublist, as in Experiment 2), the average distance from all other items is greater than that of middle items. In other words, those items are more distinctive.

The modified ratio rule represents one possible variation of a widely accepted functional principle that can accommodate the present findings while retaining a viable explanation of earlier results as well. It may be that the geometric or harmonic mean of the temporal distance between one item and all other items of a list will provide a more precise measure of temporal contrast. Or, following Murdock (1960) even more closely, a subjective measure of average temporal distance (e.g., employing a power function of time) may eventually yield the most accurate measure. Additional research on the relation between degree of temporal isolation and the magnitude of sublist serial position effects will be needed to answer these questions. In addition, because the sublist recency effect in Experiment 2 was somewhat inconsistent, the question of whether the effects of temporal separation from preceding items is symmetrical to the effects of temporal separation from subsequent items must also be addressed.

\section{Rehearsal Accounts}

Experiment 3 was concerned with evolving a functional expression concerning the role of rehearsal in single-trial free recall. Despite a substantial history of research, the role of rehearsal in producing serial position effects is still not very well understood (Modigliani \& Hedges, 1987). Experiment 3 tested the hypothesis that the effectiveness of rehearsal on delayed recall varies indirectly with the number of preceding to-be-remembered items. The results suggested that final recall was higher when words were rehearsed in the context of only a few to-be-remembered items and decreased monotonically as the number of such items increased.

This finding is new to the large literature on single-trial free recall and may open a fruitful avenue of research into the effects of rehearsal. In the past, the study of rehearsal in free recall procedures has led investigators to examine levels of processing, as well as the effects of rehearsal distribution. Both approaches have been illuminating, but neither can accommodate the rehearsal phenomenon depicted in Figures 4 and 5. The rehearsal context principle proposed to account for these results can be subjected to a rigorous test by borrowing a "forget cue" procedure such as that employed by Bruce and Papay (1972). If the number of to-be-remembered items at the time of rehearsal is the crucial variable, then it should be possible to restore rehearsal effectiveness by signaling subjects to forget all preceding items except the current rehearsal set. For example, on some lists, subjects could be allowed to devote extra rehearsal to the last few items of the list (as in Condition E of Experiment 3). On other lists, the procedure would be identical except that a tone would be sounded, indicating that only the rehearsed items need to be recalled. According to the rehearsal context hypothesis, the probability of recall in FFR for the rehearsed items in the second condition should be considerably higher than that of the first condition.

\section{Conclusion}

Long ago, Bousfield, Whitmarsh, and Esterson (1958) called for a serious effort to produce a functional analysis of free recall. Although few have apparently heeded this advice, active research generated by theories of short-term memory, especially the dual store model, has yielded several functional 
insights worthy of investigation in their own right. The premise of the present research effort is that the process may also work in reverse. That is, efforts to improve our understanding of the empirical relations that underlie single-trial free recall may eventually facilitate the development of a more comprehensive model of short-term memory.

\section{References}

Atkinson, R. C., \& Shiffrin, R, M. (1968). Human memory: A proposed system and its control processes. In K. W. Spence \& J. T. Spence (Eds.), The psychology of learning and motivation (Vol. 2, pp. 89-195). New York: Academic Press.

Baddeley, A. D. (1978). The trouble with levels: A reexamination of Craik and Lockhart's framework for memory research. Psychological Review, 85, 139-152.

Baddeley, A. D., \& Hitch, G. J. (1974). Working memory. In G. H. Bower (Ed.), The psychology of learning and motivation: Advances in research and theory (Vol. 8, pp. 47-90). New York: Academic Press.

Bjork, R. A., \& Whitten, W. B. (1974). Recency-sensitive retrieval processes in long-term free recall. Cognitive Psychology, 6, 173189.

Bousfield, W. A., Whitmarsh, G. A., \& Esterson, J. (1958). Serial position effects and the "Marbe Effect" in the free recall of meaningful words. The Journal of General Psychology, 59, 255-262.

Bower, G. H. (1971). Adaptation-level coding of stimuli and serial position effects. In M. H. Appley (Ed.), Adaptation-level theory (pp. 175-201). New York: Wiley.

Brodie, D. A., \& Prytulak, L. S. (1975). Free recall curves: Nothing but rehearsing some items more or recalling them sooncr? Journal of Verbal Learning and Verbal Behavior. 14, 549-563.

Bruce, D., \& Papay, J. P. (1972). Primacy effects in single-trial free recall. Journal of Verbal Learning and Verbal Behavior, 9, 473486.

Craik, F. I. M. (1970). The fate of primary memory items in free recall. Journal of Verbal Learning and Verbal Bchavior, 9, 143148.

Craik, F. I. M., \& Lockhart, R. S. (1972). I evels of processing: A framework for memory research. Journal of Verbal Learning and Verbal Behavior, 11, 671-684.

Craik, F. I. M., \& Watkins, M. J. (1973). The role of rehearsal in short-term memory. Journal of Verbal Learning and Verbal Behavior, 12, 599-607.

Crowder, R. G. (1970). The role of one's own voice in immediate memory. Cognitive Psychology, 1, 157-178.

Crowder, R. G. (1976). Principles of learning and memory. Hillsdale, NJ: Erlbaum.

Crowder, R. G. (1982). The demise of short-term memory. Acta Psychologia, 50, 291-323.

Dalezman, J. J. (1977). Effects of output order on immediate, delayed, and final recall performance. Journal of Experimental Psychology: Human Learning and Memory, 2, 597-608.

Fischler, I., Rundus, D., \& Atkinson, R. C. (1970). Effects of overt rehearsal procedures on free recall. Psychonomic Science, 19, 249250.

Gianutsos, R. (1972). Free recall of grouped words. Journal of Experimental Psychology, 95, 419-428.

Glenberg, A. M. (1984). A retrieval account of the long-term modality effect. Journal of Experimental Psychology: Learning. Memory, and Cognition, 10, 16-31.

Glenberg, A. M., Bradley, M. M., Kraus, T. A., \& Renzaglia, G. J. (1983). Studies of the long-term recency effect: Support for a contextually guided retrieval hypothesis. Journal of Experimental
Psychology: Learning, Memory, and Cognition, 9, 231-255.

Glenberg, A. M., Bradley, M. M., Stevenson, J. A., Kraus, T. A., Tkachuk, M. J., Gretz, A. L., Fish, J. H., \& Turpin, B. M. (1980). A two-process account of long-term serial position effects. Journal of Experimental Psychology: Human Learning and Memory, 6 , 355-369.

Glenberg, A., Smith, S. M., \& Green, C. (1977). Type I rehearsal: Maintenance and more. Journal of Verbal Learning and Verbal Behavior, 16, 339-352.

Horton, K. D. (1976). Phonemic similarity, overt rehearsal, and shortterm store. Journal of Experimental Psychology: Human Learning and Memory, 2, 244-251.

Jacoby, L. L., \& Bartz, W. H. (1972). Rehearsal and transfer to LTM. Journal of Verbal Learning and Verbal Behavior, 11, 561-565.

Kellas, G., McCauley, C., \& McFarland, C. E. (1975). Reexamination of externalized rehearsal. Journal of Experimental Psychology: Human Learning \& Memory, 104, 84-90.

Marshall, P. H., \& Werder, P. R. (1972). The effects of the elimination of rehearsal on primacy and recency. Journal of Verbal Learning and Verbal Behavior, 11, 649-653.

Melton, A. W. (1970). The situation with respect to the spacing of repetitions and memory. Journal of Verbal Learning and Verbal Behavior, 9, 596-606.

Meunier, G. F., Ritz, D., \& Meunier, J. A. (1972). Rehearsal of individual items in short-term memory. Journal of Experimental Psychology, 95, 465-467.

Modigliani, V. (1976). Effects on a later recall by delaying initial recall. Journal of Experimental Psychology: Human Learning and Memory, 2, 609-622.

Modigliani, V. (1980). Immediate rehearsal and initial retention interval in free recall. Journal of Experimental Psychology: Human Learning and Memory, 6, 241-253.

Modigliani, V., \& Hedges, D. G. (1987). Distributed rehearsals and the primacy effect in single-trial free recall. Journal of Experimental Psychology: Learning, Memory, and Cognition, 13, 426-436.

Modigliani, V., \& Seamon, J. G. (1974). Transfer of information from short- to long-term memory. Journal of Experimental Psychology, 102, 768-772.

Murdock, B. B. (1960). The distinctiveness of stimuli. Psychological Review, 67, 16-31.

Murdock, B. B. (1962). The serial position effect in free recall. Joumal of Experimental Psychology, 64, 482-488.

Murdock, B. (1974). Human memory: Theory and data. Potomac, MD: Erlbaum.

Murdock, B., \& Metcalfe, J. (1978). Controlled rehearsal in singletrial free recall. Journal of Verbal Learning and Verbal Behavior, 17, 309-324.

Murdock, B. B., \& Walker, K. D. (1969). Modality effects in free recall. Journal of Verbal Learning and Verbal Behavior, 8, 665676.

Nelson, T. O. (1977). Repetition and depth of processing. Journal of Verbal Learning and Verbal Behavior, 16, 151-171.

Roediger, H. L., \& Schmidt, S. R. (1980). Output interference in the recall of categorized and paired-associate lists. Journal of Experimental Psychology: Human Learning and Memory, 6, 91-105.

Roenker, D. L. (1974). Role of rehearsal in long-term retention. Journal of Experimental Psychology, 103, 368-371.

Rundus, D. (1971). Analysis of rehearsal processes in free recall. Journal of Experimental Psychology, 89, 63-77.

Rundus, D. (1977). Maintenance rehearsal and single-level processing. Journal of Verbal Learning and Verbal Behavior, 16, 665-681.

Shaughnessy, J. J. (1981). Memory monitoring accuracy and modification of rehearsal strategies. Journal of Verbal Learning and Verbal Behavior, 20, 216-230. 
Thorndike, E. L., \& Lorge, I. (1944). The teacher's word book of 30,000 words. New York: Columbia University Press.

Tulving, E., \& Arbuckle, T. Y. (1963). Sources of intratrial interference in immediate recall of paired associates. Journal of Verbal Learning and Verbal Behavior, 1, 321-334.

Tzeng, O. J. L. (1973). Positive recency effect in a delayed free recall. Journal of Verbal Learning and Verbal Behavior, 12, 436-439.

Underwood, B. J. (1969). Some correlates of item repetition in freerecall learning. Journal of Verhal Learning and Verbal Behavior, 8, 83-94. von Restorff, H. (1933). Über die wirkung von bereichsbildungen im spurenfeld [On the effects of the organization of the surround on the trace field]. Psychologische Forschung, 18, 299-342.

Waugh, N. C., \& Norman, D. A. (1965). Primary memory. Psychological Review, 72, 89-104.
Received February 29, 1988

Revision received August 22, 1988

Accepted September 23, 1988

\section{Low Publication Prices for APA Members and Affiliates}

Keeping You Up-to-Date: All APA members (Fellows; Members; and Associates, and Student Affiliates) receive--as part of their annual dues--subscriptions to the American Psychologist and the APA Monitor.

High School Teacher and Foreign Affiliates receive subscriptions to the APA Monitor and they can subscribe to the American Psychologist at a significantly reduced rate.

In addition, all members and affiliates are eligible for savings of up to $50 \%$ on other APA journals, as well as significant discounts on subscriptions from cooperating societies and publishers (e.g., the British Psychological Society, the American Sociological Association, and Human Sciences Press).

Essential Resources: APA members and affiliates receive special rates for purchases of APA books, including the Publication Manual of the APA, the Master Lectures, and APA's Guide to Research Support.

Other Benefits of Membership: Membership in APA also provides eligibility for low-cost insurance plans covering life; medical and income protection; hospital indemnity; accident and travel; Keogh retirement; office overhead; and student/school, professional, and liability.

For more information, write to American Psychological Association, Membership Services, 1200 Seventeenth Street NW, Washington, DC 20036, USA. 